\title{
DOSSIÊ: MÉTODOS E EXPLICAÇÕES DA POLÍ́TICA*
}

* Dossiê organizado a partir de mesa redonda realizada no $30^{\circ}$ Encontro Anual da ANPOCS, Caxambu - MG, outubro de 2006. 


\section{LEIS GERAIS, EXPLICAÇÕES E MECANISMOS}

\section{Para onde vão nossas análises?}

\section{Eduardo Marques}

O presente Dossiê inclui intervenções apresentadas em mesa redonda sobre explicações na ciência política realizada durante o XXX Encontro Anual da Anpocs. Os textos aqui incluídos discutem métodos e explicações sobre a política, enfocando sobretudo abordagens recentes, como os mecanismos institucionais e relacionais, o lugar da história e a contribuição da antropologia da política. Embora essas quatro perspectivas variem substancialmente em termos de abrangência, têm todas exercido importante impacto sobre o desenvolvimento de estudos sobre a política em período recente, tanto internacionalmente como no Brasil. Apesar disso, ainda carecemos de publicações que as tenham sistematizado nos principais elementos e mecanismos mobilizados pelas explicações. Contribuir para o preenchimento de tal lacuna é o objetivo deste Dossiê.

A discussão sobre método é relativamente rara entre nós, visto que não temos tradição de pensar em nossas explicações, nem tampouco nos modelos de análise que são mobilizados por nossa produção científica. Na verdade, essa discussão é muitas vezes substituída por falsas oposições entre elementos necessariamente complementares para a produção do conhecimento. Acredito que o problema tenha várias origens, e embora conheça melhor o caso da ciência política parece-me que também atinge as demais disciplinas. Pretendo nesta apresentação estabelecer alguns pontos preliminares. Não se trata de esgotar as questões destacadas, mas de diferenciar alguns elementos presentes nesse debate.

Em primeiro lugar, o espaço da discussão sobre método é, por vezes, ocupado entre nós por falsas dicotomias entre técnicas ou entre teoria e análise empírica. Com efeito, essa dicotomia ecoa oposições clássicas entre dedutivismo e "testemunho das coisas" na história da ciência que o desenvolvimento do conhecimento e a sua análise recente pelas ciências sociais superaram ou reintegraram (Latour, 2005). A maior parte do 
ensino de metodologia em nossos cursos, por exemplo, oscila entre a apresentação dos paradigmas teóricos de uma determinada disciplina e o ensino das técnicas de pesquisa ali presentes.

No que diz respeito às técnicas, além disso, somos até mesmo mobilizados para nos posicionar em relação à superioridade de certas técnicas sobre outras, como, por exemplo, na falsa oposição entre quantitativo e qualitativo. Talvez este seja o equívoco mais grave que se pode incorrer na matéria em pauta. Técnicas de pesquisa devem ser apenas aplicadas de forma correta (sob o ponto de vista de seus elementos técnicos) e apropriada para um certo objeto e um conjunto de perguntas e objetivos de pesquisa. As polêmicas abstratas e principistas sobre técnicas ou sobre estratégias analíticas são completamente desprovidas de sentido científico e servem apenas para ocultar conflitos de interesse e poder no interior da comunidade acadêmica e de suas instituições. Por vezes representam até mesmo uma defesa em relação a desconhecimentos e incapacidades. O avanço do conhecimento depende, diferentemente, da discussão de interpretações e argumentos a respeito de fenômenos.

Apesar disso, é verdade que enfrentamos um problema localizado no que diz respeito às técnicas. A produção científica brasileira, em geral, e o ensino de ciências sociais, em particular, apresentam uma lacuna significativa no campo das técnicas de pesquisa, sejam elas quantitativas ou qualitativas, sejam exploratórias ou analíticas. O problema é causado em parte por um círculo vicioso, visto que poucos entre nós foram formados (quando estudantes) para ensinar esse assunto, o que mantém as novas gerações de cientistas sociais pouco conhecedoras das principais ferramentas técnicas existentes.

Uma outra falsa oposição presente com alguma freqüência entre nós diz respeito às estratégias de pesquisa. Assim como no caso anterior, a realização de investigações mediante estudos de caso ou estudos de variáveis com grande número de casos representa uma escolha importante entre estratégias de pesquisa, mas que deve apenas ser apropriada aos objetos estudados e às perguntas que o trabalho pretende responder. Como já fartamente discutido pela literatura internacional, as escolhas analíticas representam decisões com relação a ênfases. A utilização de uma estratégia baseada em um grande número de casos com poucas variáveis (usualmente quantificadas) permite, na maior parte das vezes, uma capacidade de generalização elevada, mas, por definição, leva o analista para longe dos detalhes e restringe o conjunto de elementos que podem ser estudados conjuntamente (Przeworski e Teune, 1970). Por outro lado, estudos baseados em casos estão muito mais interessados nos detalhes e tiram a sua capacidade de análise do entrelaçamento e da ordem dos fenômenos e das variáveis (Ragin, 1987), em troca de uma maior dificuldade de generalizar. A generalização e a compreensão dos detalhes e da variabilidade dos fenômenos somente podem ser alcançadas por meio da combinação dessas duas estratégias, tarefa que é normalmente realizada com o trabalho cooperativo no interior da comunidade científica entre perspectivas diferentes.

Embora essas várias escolhas sejam importantes, a questão mais geral a que me referi anteriormente não se resume a elas, mas se encontra nas estruturas da explicação, ou no maior ou menor controle dos pesquisadores sobre seus próprios argumentos.

O ponto de partida de todo o conhecimento em ciências sociais é a idéia de que é possível observar e interpretar as regularidades do mundo social, sem que isso signifique a abolição das variações individuais. Isso pode parecer óbvio, mas representa uma primeira distinção com relação a perspectivas céticas que defendem a impossibilidade de construirmos explicações em nossas ciências. Além de assumirmos uma postura não cética em relação ao conhecimento, entretanto, quase todos nós partimos de uma visão probabilística dos fenômenos no mundo social (Przeworski e Teune, 1970), incluindo autores que não abordam os seus fenômenos quantitativamente. Probabilístico tem aqui um sentido ontológico e descreve o fato de que os fenômenos sociais sempre variarão de um caso para outro. Nesse sentido, o tipo de explicação que podemos produzir é diferente de grande parte das produzidas nas ciências físicas, em que a maioria dos fenômenos é entendida como determinística, sendo possível prever o comportamento futuro dos fenômenos incorrendo-se apenas em erros de medida. $\mathrm{Na}$ 
verdade, esse tipo de explicação era amplamente hegemônico sob o paradigma da física newtoniana, mas hoje nem mesmo nas chamadas ciências duras a determinação faz mais parte das explicações responsáveis pelos mais importantes desenvolvimentos (Prigogine, 1996). De qualquer forma, no caso dos fenômenos sociais, as variações em relação ao previsto por um determinado modelo explicativo não se devem apenas aos erros de nossos "instrumentos de medida", ou às complexas multicausalidades do mundo social (King, Keohane e Verba, 1994), mas à variabilidade da ocorrência dos fenômenos no mundo social (King, Keohane e Verba, 1994; Przeworski e Teune, 1970). Isso ocorre mesmo quando há acordo a respeito de explicações, para além das diferenças de perspectiva sociais e éticas que marcam o conhecimento na área. Por todas essas razões, portanto, a construção de teorias de médio alcance parece ser para nós a postura analítica mais parcimoniosa, ao menos como estratégia provisória de produção cumulativa do conhecimento em ciências sociais.

A discussão detalhada desses pontos, entretanto, nos levaria para longe de nosso argumento. Para os objetivos deste debate, basta que estabeleçamos que a produção do conhecimento é possível e que nossos fenômenos tem uma ontologia probabilística, comportando variações em torno dos casos. Dado isso, uma das grandes clivagens presentes no debate diz respeito ao estatuto e às estratégias de nossas explicações. Esse ponto é analisado por vários autores de forma dispersa, e em Tilly (2001) de maneira mais explícita. Embora a classificação que esse autor propõe apresente alguns problemas, é bastante útil como ponto de partida.

Para Tilly, há basicamente quatro tipos de explicação, além da perspectiva cética (que representa, de fato, a recusa da possibilidade de explicações). Em primeiro lugar, as "leis gerais", em que o esforço recai sobre a construção de generalizações amplas baseadas em informações empíricas de grande envergadura. Neste caso, a pesquisa é organizada metodologicamente como uma grande coleção de informações, controlando as variações em torno do que seriam médias estatísticas e apontando para as condições associadas à ocorrência de um determinado fenô- meno. As informações podem ser qualitativas ou quantitativas, mas, ao final, passam por alguma forma de quantificação. Quando as leis gerais centram a sua atenção na existência de motivações e cognições, Tilly as considera um segundo tipo de explicação denominado "explicação por propensões". Com grande freqüência, em ambos os casos os estudos mobilizam o que Mahoney (2001) chama de análise de correlação em um sentido lato.

Um terceiro conjunto de explicações de grande generalidade incluiria as sistêmicas, segundo Tilly. Neste caso, as análises compreendem a ocorrência de um dado fenômeno a partir do lugar que ele ocupa em uma estrutura ou sistema com funcionamento preestabelecido pela teoria. O funcionamento dos fenômenos é considerado automático e autoregulado, sendo derivado de processos e eventos que ocorrem sem a necessidade direta de ação social ou atores.

Por fim, um quarto e amplo conjunto de explicações mobiliza mecanismos e processos, indicando elementos singulares como causas e recorrendo a analogias explicativas parciais e localizadas. Os elementos mobilizados aqui estão próximos da ação social e situam-se, portanto, em um nível menos abstrato do que nos três tipos de explicação anteriores. Mahoney ajuda a precisar ainda mais o argumento, ao definir que um "mecanismo causal é uma entidade não observada que, quando ativada, gera um resultado de interesse" (2001, p. 580). Essa definição pareceme bastante interessante, pois não apenas chama a atenção para a dimensão suficiente dos mecanismos (que os diferenciam de meras variáveis intervenientes), mas principalmente destaca o fato de que "os mecanismos causais são relações postuladas que o pesquisador imagina que existam" (Idem, p. 581). Isso é de fundamental importância, uma vez que remete à ontologia dos mecanismos, indicando que eles não estão no mundo social, mas em nossas teorias. As explicações por mecanismos, portanto, não intencionam descobrir a existência de um dado elemento da sociedade, mas abrir a "caixa-preta" da causação de determinados fenômenos, levando a uma melhor compreensão das dinâmicas sociais.

Tilly descreve três tipos de mecanismos: ambientais, cognitivos e relacionais. No primeiro 
caso, temos ações que se vinculam a características dos contextos que influenciam a vida social. Dentre esses, podemos incluir as instituições, destacadas pelo neoinstitucionalismo, e o espaço ou o território, destacados pela geografia e os estudos urbanos e regionais. Os mecanismos cognitivos incluem as ações que se relacionam com as percepções e os estados mentais dos indivíduos e grupos sociais, englobando as várias explicações derivadas da teoria da escolha racional e suas aparentes violações, como $\mathrm{O}$ devaneio e a compensação. A maior parte dos elementos classificados por Elster (1998) como mecanismos pode ser incluída nessa categoria. Por fim temos os chamados mecanismos relacionais, que, de alguma forma, mobilizam as relações entre indivíduos, grupos e organizações, assim como os padrões gerais formados por tais conjuntos de relações, conformando redes sociais.

Parece-me que a classificação de Tilly confunde a ambição das explicações (presente nos três primeiros conjuntos de explicação) com a localização do elemento causal (presente nos mecanismos). Assim, é possível que sustentemos que um determinado mecanismo é de tal forma importante que ocorre sempre e, portanto, é o fundamento de uma lei geral. Nesse sentido, as explicações por mecanismos, apesar de se localizarem em níveis de abstração inferior aos descritos pelo primeiro conjunto, podem almejar uma generalização elevada. A força de sua classificação, entretanto, diz respeito à proposição dos tipos de mecanismos, o que me parece bastante importante para organizarmos as explicações que temos produzido.

Em nosso caso específico, se articulamos essa classificação com o que afirmei anteriormente em relação às teorias de médio alcance, parece-me que a postura mais parcimoniosa a adotar está em buscar os mecanismos e os processos de nível intermediário que explicam os fenômenos, em uma estratégia ao mesmo tempo provisória e cumulativa de produção do conhecimento. Os textos que compõem este Dossiê partem desse ponto de vista. Marta Arretche discute os principais elementos mobilizados em um tipo de explicação ambiental, de natureza institucional, que tem sido objeto de intenso uso e debate nas últimas décadas. Em seguida, Gilberto Hochman apresenta os principais elementos que as abordagens históricas comportam, focando para além da dimensão de cenário histórico e avançando na direção da especificação dos mecanismos históricos que cercam e influenciam as dinâmicas políticas. O terceiro artigo, de minha autoria, discute os avanços recentes trazidos pelo estudo dos mecanismos relacionais enfocados pela análise de redes sociais, campo já bastante amplo internacionalmente, mas infelizmente pouco disseminado entre nós. Por fim, Karina Kuschnir explora a abordagem da antropologia da política, problematizando nossas representações sobre a política (dos pesquisadores e dos próprios atores políticos) e contribuindo para um melhor entendimento dos mecanismos cognitivos tão caros a diversas tradições do estudo da política.

\section{BIBLIOGRAFIA}

ELSTER, J. (1998), "A plea for mechanisms", in P. Hedstrøm e R. Swedberg (orgs.), Social mechanisms: an analytical approach to social theory, Cambridge, Cambridge University Press.

KING，G.; KEOHANE，R. \& VERBA， S. (1994), Designing social inquiry: scientific inference in qualitative research. Princeton, Princeton University Press.

LATOUR, B. (2005), Jamais fomos modernos. São Paulo, Editora 34.

MAHONEY, J. (2001), "Beyond correlation analysis: recent innovations in theory and method". Sociological Forum, 16 (3).

PRIGOGINE, I. (1996), O fim das certezas: tempo, caos e leis da natureza. São Paulo, Editora da Unesp.

PRZEWORSKI, A. \& TEUNE, H. (1970), The logic of comparative social inquiry. Malabr, $\mathrm{R}$. Krieger Pub. Company

RAGIN, C. (1987), The comparative method: moving beyond qualitative and quantitative strategies. Berkeley, University of California Press.

RAGIN, C. (2006), "How to lure analytic social science out of the doldrums: some lessons 
form comparative research". International Sociology, 21 (5).

TILLY, C. (2001), "Mechanisms in political processes". Annual Review of Political Science, 4. 
DOSSIÊ: MÉTODOS E EXPLICAÇÕES DA POLÍTICA

\author{
Eduardo Cesar Leão Marques \\ Marta Arretche \\ Gilberto Hochman \\ Karina Kuschnir
}

\section{Palavras-chave}

Explicações; Mecanismos; Neoinstitucionalismo, História, Redes sociais e Antropologia da política

Trata-se de um dossiê sobre método no estudo da política. São discutidas metodologias crescentemente utilizadas em período recente, enfocando-se inicialmente elementos relativos à ontologia da política, aos processos analisados e ao próprio estatuto explicativo das diferentes perspectivas. Posteriormente, são discutidos de maneira mais detalhada os avanços trazidos pela análise neoinstitucionalista, pelos estudos históricos, pela análise de redes sociais e pela antropologia da política.
DOSSIER: METHODS AND POLITICAL EXPLANATIONS

Eduardo Cesar Leão Marques

Marta Arretche

Gilberto Hochman

Karina Kuschnir

\section{Keywords}

Explanations, Mechanisms; Neoinstitutionalism, History, Social networks, Political anthropology

This is a dossier on method in studying politics. Prevailing methodologies are discussed focusing initially on elements relating to political ontology, processes analyzed, and the very explicative statute of different perspectives. Afterwards, advances brought by neoinstitutionalist analysis, historical studies, social network studies, and political anthropology are more carefully discussed.
DOSSIER: MÉTHODES ET EXPLICATIONS DE LA POLITIQUE

Eduardo Cesar Leão Marques

Marta Arretche

Gilberto Hochman

Karina Kuschnir

\section{Mots-clés}

Explications; Mécanismes; Néoinstitutionnalisme; Histoire; Réseaux sociaux; Anthropologie de la politique

Il s'agit d'un dossier sur la méthode dans l'étude de la politique. Des méthodologies de plus en plus employées dans la période récente sont discutées. Nous nous attachons initialement aux éléments relatifs à l'ontologie de la politique, aux processus analysés et au propre statut explicatif des différentes perspectives. Postérieurement, nous abordons de manière plus détaillée les avancées dues à l'analyse néoinstitutionnaliste, par les études historiques, par l'analyse de réseaux sociaux et par l'anthropologie de la politique. 